\title{
The First World Diagnosis of Allergy
}

\author{
Arnaldo Cantani* \\ Pediatric Clinic, University "La Sapienza” Roma, Italy
}

Submission: January 19, 2017; Published: January 25, 2017

*Corresponding author: Arnaldo Cantani, Pediatric Clinic, University “La Sapienza” Roma, Italy

\begin{abstract}
Six infants were affected with intractable diarrh?ea and therefore admitted to our ward. That was the birth of allergy, which revolutionized the medical world. Such as Jobs changed our way of living, we insured to sick babies and children a new way of living with allergy, when not escaping it the figures 1-3 show a rare microscopic appearance of the immune cells involved in an oral provocation test. About 40 years ago the whole world lived in the complete ignorance of allergy. We have made the first world diagnosis of allergy and of cow's milk allergy (CMA) in six parenterally fed babies.
\end{abstract}

Abbreviations: CMA: Cow's Milk Allergy; CM: Cow's Milk; MM: Maternal Milk

\section{Introduction}

The first world diagnosis of cow's milk allergy (CMA) has been made in six critically ill children, aged a few months, admitted to the Department of Pediatrics of the Roma University in 1974-75 and recovered in our ward, because afflicted with "intractable" diarrhea and fed parenterally who were first world diagnosed by us. CMA is a severe even perinatal disease [1]. The infants were parenterally fed with all the necessary alimentation. By reviewing their charts, in a shabby chamber which resembled the cottage of the twin's founders of Rome, so science was highlighted, we read that among their feeding there was the casein [2]. Then the destiny knocked at our door. We looked at our documentation, we were astonished. The casein was the most severe cause of allergy, due to cow's milk (CM) [3]. It was also the birth of pediatric allergy and immunology science. For a complete nutrition they were also fed with casein in the ward, therefore the diarrhea persisted and aggravated continuously.

Materials and Methods

\section{Study children}

Table 1: The daily parenteral nutrition contained as follows.

\begin{tabular}{|c|c|}
\hline Aminosol liquid & $\begin{array}{c}380 \mathrm{ml} \text { (a solution containing concentrated essential and non } \\
\text { essential amino acids) }\end{array}$ \\
\hline glucose & $40 \%, 120 \mathrm{ml}$ \\
\hline Ca glucosate & $5 \% 10 \mathrm{ml}$ \\
\hline K phosphate & $10 \mathrm{mEq}$ \\
\hline $\mathrm{NaCl}$ & $5 \mathrm{mEq}$ \\
\hline
\end{tabular}

In those times (1974-1975) we had a hard job in finding the CM allergens therefore we used initially pure CM in powder so obtaining a huge reaction. Subsequently we were able to confirm the diagnosis with regular allergens. In those heroic times we had a rich collection of cases. Several babies were fed maternal milk (MM), but when they received a diet, the substitute was CM diᄀluted 2:1 or 3:1 because of the fat difference between MM and CM [3]. The editor of Annals of Allergy initially refused the paper, with perfect aplomb, because at his eyes it was impossible, thus the paper with the first world diagnosis of CM allergy (CMA) must wait for publication. If I had surrendered myself to the impossible, I had not the Pediatric Allergy, Asthma and Immunology (in internet) selling seven thousands of copies and two hundreds/a month even in the 4. year of printing [4] CMA has a very high prevalence, from 0,013 to $45,4 \%$ [4] and severity especially in the first year of life. 
Global Journal of Addiction \& Rehabilitation Medicine

\begin{tabular}{|c|c|}
\hline Ca & $4 \mathrm{mEq}$ \\
\hline $\mathrm{Mg}$ & $6 \mathrm{mEq}$ \\
\hline $\mathrm{Cl}$ & $10 \mathrm{mEq}$ \\
\hline methicillin & $500 \mathrm{mg}$ \\
\hline \multicolumn{1}{|c|}{ The daily semisynthetic diet contained as follows: } \\
\hline $\mathrm{H}_{2} \mathrm{O}$ & $1000 \mathrm{ml}$ \\
\hline glucose & $60 \mathrm{~g}$ \\
\hline Ca caseinate & $30 \mathrm{~g}$ \\
\hline olive oil & $40 \mathrm{mg}$ \\
\hline a saline mixture & $(\mathrm{KCl} 45 \%, \mathrm{NaCl} 45 \%, \mathrm{CaHPO} 410 \%) 5 \mathrm{~g}$ \\
\hline The whole content of calories was & 720 \\
\hline Laboratory tests & \\
\hline
\end{tabular}

The study was done in 1974-75, in six babies aged 17 days-11 months, three males and three females, who were hospitalized because they were severely ill because diagnosed as suffering from chronic diarrhea with severe malnutrition and were therefore fed parenterally. The disease onset varied between a few days and a few weeks, when CM was started, It is important that the babies had not a stool improvement when fed soy milk, therefore some were parenterally fed, some were luckily MM fed. Six infants suffering from chronic diarrhea due to glutensensitive enteropathy served as controls for the allergy tests.

The daily parenteral nutrition contained as follows: (Table 1).

We devised for the first time in the world a complete set of Skin Prick Tests (SPTs)

\section{SPT making}

Appropriate emergency equipment and medications were available on site. All possible drugs were stopped at least 2 weeks before the application of the SPTs. Six healthy babies of the same age and sex with the permission of their parents. Skin testing was done at baseline by the prick method on the volar surface of the fore-arm by a trained in allergy doctor with the co-operation of a qualified nurse. The skin was marked with a ballpoint pen for the allergens to be tested. The babies were then tested with: histamine hydrochloride $(1 \mathrm{mg} / \mathrm{ml})$ as a positive control and isotonic saline as a negative control. We continued with a battery of food allergens, including whole CM protein, beta-lactoglobulin, casein, lactalbumin (Lofarma). The diagnostic extract of each individual allergen was placed on the volar surface of the forearm as drops through which the skin was superficially pricked with a straight pin for one second. A new pin was used for each SPT and then discarded, and the drop of the extract was then wiped off about one minute after the prick.

\section{SPT reading (Table 2)}

We took for positive only children with a +++ or ++++ reaction, that is a wheal $\gg 3 \mathrm{~mm}$ with an area $=7 \mathrm{~mm} 2$ (cutoff). So we considered as positive only the children with a mean wheal diameter of $3 \mathrm{~mm}$ or larger than the negative (saline) control. A positive (histamine) control was performed to ensure the absence of any antihistamine drug interference.

Table 2: SPTs were read 20 minutes after the test was finished and considered positive as follows.

\begin{tabular}{|c|}
\hline+ When the wheal was the half of the histamine wheal \\
\hline++ When the wheal was equal to the histamine wheal \\
\hline+++ When the wheal was two-fold the histamine wheal \\
\hline++++ When the wheal was more than two-fold the histamine wheal \\
\hline
\end{tabular}

\section{Statistical analysis}

Table 3: Clinical manifestations ascribed to CMA: The symptoms and disorders sometimes believed to be caused by CMA are numerous, but almost none of them are pathognomonic of CMA.

\begin{tabular}{|c|}
\hline Systemic: hypotension, shock \\
\hline $\begin{array}{c}\text { GI: colitis, irritable colon, flatulence, diarrhea, abdominal pains } \\
\text { (colics), gengivitis, malabsorption; nausea, constipation, stomatitis, } \\
\text { vomiting }\end{array}$ \\
\hline $\begin{array}{l}\text { Respiratory: extrinsic allergic alveolitis, recurrent respiratory } \\
\text { infections, up } \mathrm{p} \text { per airway obstruction, recurrent pneumonia (Heiner } \\
\text { syndrome), rhinitis, serous otitis, sinusitis, laryngeal edema. } \\
\text { pulmonary hemosiderosis, chronic cough, bronchitis, wheezing, } \\
\text { dyspnea, recurrent fever }\end{array}$ \\
\hline $\begin{array}{c}\text { cutaneous: alopecia, angioedema, herpetiform dermatitis, eczema, } \\
\text { urticaria, purpura, erythematous macular rash }\end{array}$ \\
\hline $\begin{array}{l}\text { Hematologic: iron-deficiency anemia, thrombocytopenia, gross/ } \\
\text { occult bloody stools }\end{array}$ \\
\hline $\begin{array}{l}\text { Urinary: albuminuria, cystitis, enuresis, minimal lesion } \\
\text { glomerulonephritis, nephrotic syndrome }\end{array}$ \\
\hline $\begin{array}{l}\text { Central nervous: migraine, epilepsy, attention deficit hyperactivity } \\
\text { disorder, restless legs syndrome, chronic fatigue syndrome, tension- } \\
\text { fatigue syndrome }\end{array}$ \\
\hline Ocular: keratitis, uveitis \\
\hline $\begin{array}{c}\text { Various: rheumatoid arthritis (seronegative), insulin-dependent } \\
\text { diabetes mellitus, recurrent periostitis, SIDS (sudden infant death } \\
\text { syndrome) etc. }\end{array}$ \\
\hline
\end{tabular}




\section{Global Journal of Addiction \& Rehabilitation Medicine}

The statistical analysis was performed using the X2 test. Results with a $\mathrm{p}<0.05$ were considered as statistically significant. At the CM reintroduction, for diagnostic purposes, all babies presented again with diarrhea, one with a short state of shock promptly regressed after immediate parenteral treatment. Hypersensitivity reactions to CM induce an onset of cutaneous, respiratory, and gastroenteric tract symptoms and we can then divide by systems the CM credited clinical manifestations. We studied the clinical manifestations attributed to CMA (Table 3 ). We then studied the manifestations attributed to CMA on immunological and nonimmunological basis (Tables $4 \& 4.1$ ).

Table 4: Clinical manifestations attributed to CMA on immunological and nonimmunological basis on immunological basis: unanimous.

\section{1) Type I: IgE-mediated reactions}

\section{a) Systemic}

Anaphylactic shock

b) Gastrointestinal

Early-onset enteropathy

Nausea, colics, diarrhea, vomiting, abdominal pain

Allergic eosinophilic gastroenteritis (some forms)

c) Cutaneous

Atopic dermatitis, erythema

Urticaria-Angioedema

d) Respiratory

Wheezing, sneezing, cough, rhinorrhea

Rhinoconjunctivits

\section{2) Type II: Cytotoxic reactions}

CM-induced thrombocytopenia

Recurrent pneumonia (Heiner syndrome)

3) Type III: by immune complexes

Celiac disease

Colitis syndrome

Dermatitis herpetiformis

Serous otitis

Enterocolitic syndrome

Malabsorption syndrome

Pulmonary hemosiderosis

Sideropenic anemia sometimes with occult blood loss

4) Type IV: Cell-mediated hypersensitivity

Celiac disease

Dermatitis herpetiformis

Enterocolitic syndrome

Malabsorption syndrome

Pulmonary hemosiderosis
Table 4.1: On nonimmunological basis: not unanimous.

Attention deficit hyperactivity disorder Crohn's disease Eosinophilic enteropathy Gastroesophageal reflux Infantile colitis Insomnia

Recurrent periostitis Recurring stomatitis Tension-fatigue syndrome Vasculitis

\section{Diagnosis and Differential Diagnosis}

The infants were diagnosed as having chronic diarrhea due to CMA if they fulfilled:

1) Diarrhea persisting more than 3 weeks, with subsequent failure to thrive,

2) Positive response to $\mathrm{CM}$ elimination diet,

3) Positive SPTs to casein and lactalbumin,

4) Exclusion of other causes of infantile chronic diarrhea, such as cystic fibrosis, lactase deficiency, infections, immunodeficiency.

Before each infant was admitted to the study, parents' informed consent was obtained In those far times we made an additional exclusion diagnosis with the primary lactose intolerance since the children well tolerated MM, whereas they did not recover by drinking whole $\mathrm{CM}$ or a synthetic diet without casein and deprived of lactose. Gluten intolerance was excluded since the disturbing symptoms presented themselves previously from the first gluten eating

\section{Results}

Table 5: All studied babies tested positive to $\mathrm{CM}$ and $\mathrm{CM}$ allergens, since they were suffering mostly from gastrointestinal symptoms (vomiting, diarrhea, as well as failure to thrive, one also showed lip edema). They were fed a diet containing.

\begin{tabular}{|c|}
\hline Lamb's meat devoid of fat and boiled g 100 \\
\hline Olive oil g 40 \\
\hline Rice flour g 70 \\
\hline Ca according to baby weight \\
\hline Vitamin D $400 \mathrm{U}$ \\
\hline Water up to one liter \\
\hline
\end{tabular}

All studied babies tested positive to $\mathrm{CM}$ and CM allergens, since they were suffering mostly from gastrointestinal symptoms (vomiting, diarrhea, as well as failure to thrive, one also showed lip edema). They were fed a diet containing (Table 5). The meat was fresh or frozen lamb's meat, free of both fat and tendons, cut into small pieces, boiled, minced, and then mixed with the other components of the diet. In addition we gave two fruits, bananas and apples. Once obtained the clinical improvement with this CM-free diet, diarrhea subsided after six days (median) and infants thrived again after 15 days (median). After clinical improvement started, we gave also lactose and saccharose, as well as selected vegetables and additional foods always excluding $\mathrm{CM}$ and foods CM-containing, and veal meat. Gradually the babies growth improved. 


\section{Global Journal of Addiction \& Rehabilitation Medicine}

The examination of the peripheral blood, following the oral provocarion test with CM allergens showed an accelerated lymphomonocytic response with a great number of lymphocites already at the second hour after the test. In addition there were several monocytes showing plasmocytic aspects, immunoblasts eosinophils and mastocytes, some in a state of degranulation (Figures 1-3). We have noted that no baby had neither a globose abdomen anymore, nor foamy stools as seen in celiac disease The family history for atopy was positive in the six families, most fathers than mothers suffering from atopy The controls had negative results, the statistical analysis differed significantly between studied babies and controls.

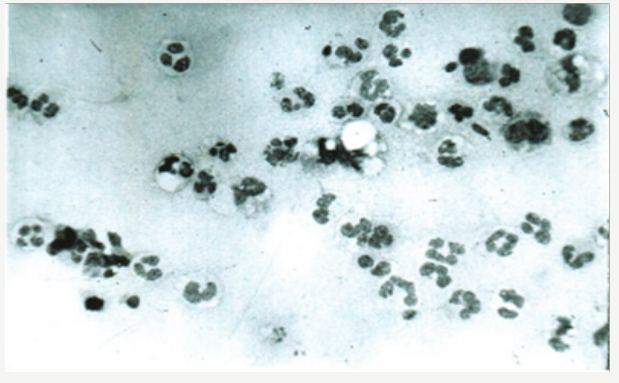

Figure 1: Lymphomonocytic response at the second hour after the provocation test.

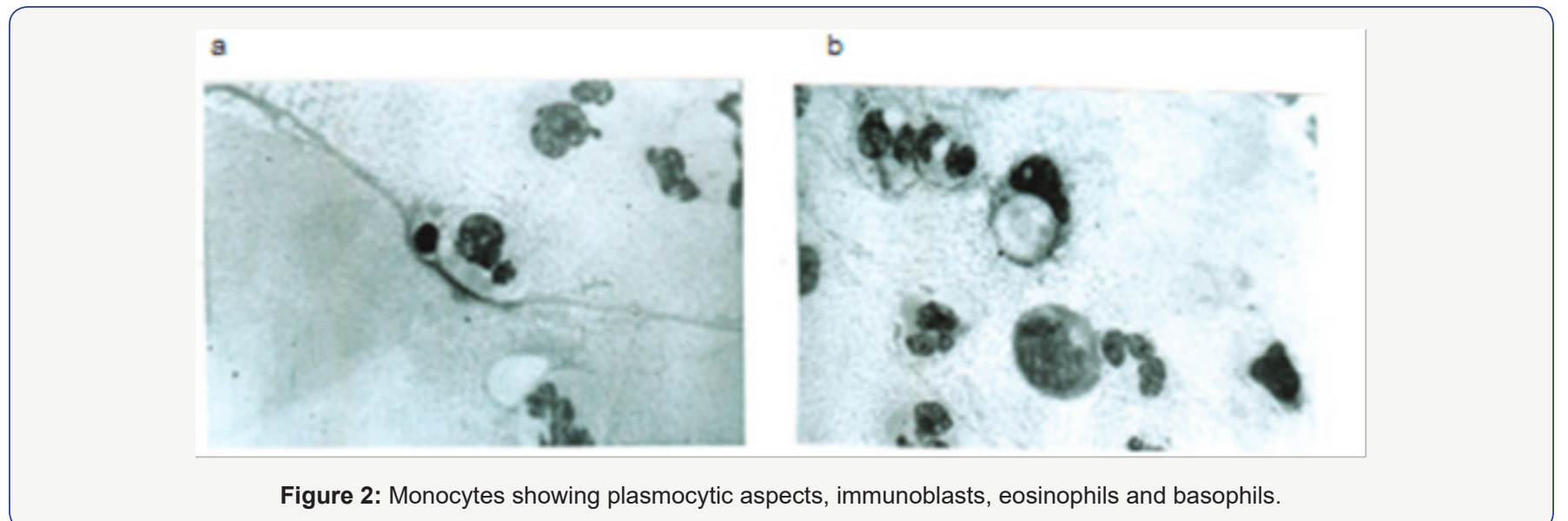

Figure 2: Monocytes showing plasmocytic aspects, immunoblasts, eosinophils and basophils.
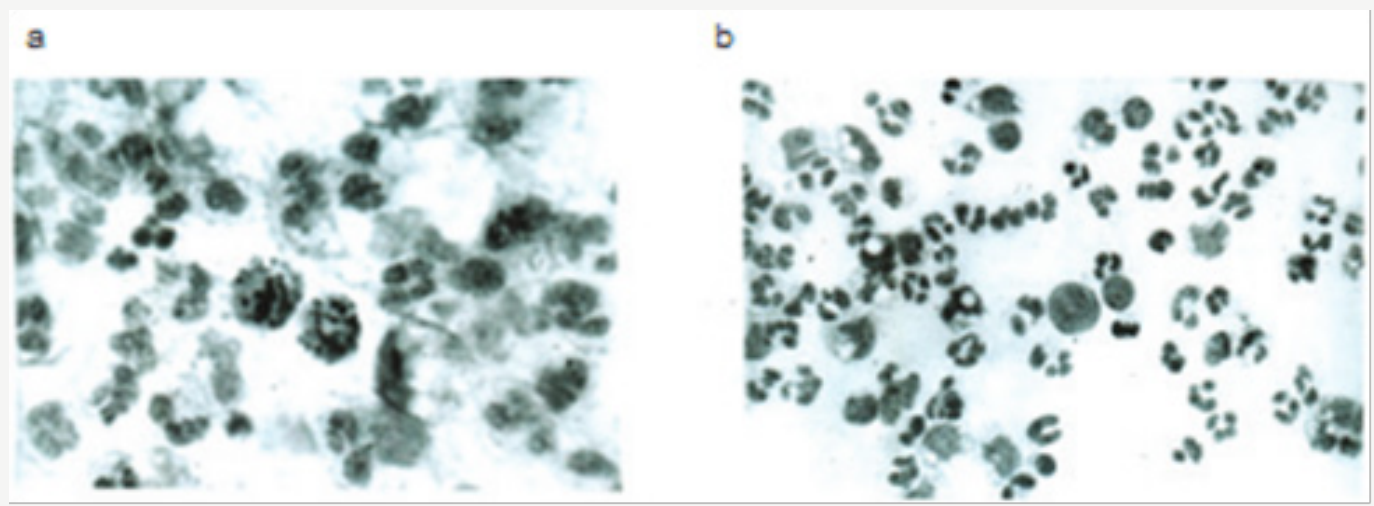

Figure 3: Histiomoncytes that phagocyte and digest the allergens, in a trial of defense.

\section{Discussion}

We have done the first world CMA diagnosis in the universe, a fact that was also the birth of pediatric allergy and immunology science. We would never have thought it, that the first world diagnosis of allergy would open such a wide catalogue of CMA attacks. A new discovery was that allergy; CMA and asthma were prompted and sustained by hereditary factors [5]. Nwaru et al. [6] have studied 994 children. Sensitization to CM allergen was present in $12 \%$ of the children, egg allergen in $9 \%$, wheat allergen in $5 \%$, and fish allergen in $1 \%$. However the study is important because it demonstrates the strong association of additional allergens with disease. Late introduction of potatoes
(4 months), oats (5 months), rye (7 months), wheat (6 months), meat (5.5 months), fish (8.2 months), and eggs (10.5 months) was significantly directly associated with sensitization to food allergens. Late introduction of potatoes, rye, meat, and fish was significantly associated with sensitization to any inhalant allergen.

In models that included all solid foods that were significantly related to the end points, eggs, oats, and wheat remained the most important foods related to sensitization to food allergens, whereas potatoes and fish were the most important foods associated with inhalant allergic sensitization [6]. Although this study in six infants is limited, it is interesting to note that the 
female group had a subsidence of diarrhea prior to the male group We stress that family history was positive in all the six families $(5 ß)$, We have diffused a home-made formula with lamb meat, rice flour for children suffering from food allergy [7]. The case here reported confirm that CMA in infants can be a clinical disease of so a high severity that a parenteral nutrition is required. In our population this was necessary for rather long periods. The attempts at instituting a soy or synthetic diet alimentation failed as expected, a baby could be fed MM for two weeks, and the results were excellent. We suggest to continue MM in all severely ill infants, where indicated. However the lamb diet has solved all cases, even in the proportion of seriously treated babies in this study. To conclude, CMA can be the causative source of much severe diarrhea and dystrophy in infants. The diagnosis can be done on symptoms and on immune test. No struggle for breastfeeding for allergy prevention is still working today [8].

\section{Conclusion}

In conclusion, we stress that the first world diagnosis of allergy and of CMA has revolutionized indeed the world of allergy and immunology, and perhaps of genetics. It has since then opened a new window on the allergic-immunologic plethora of diseased children. As Jobs invented a new way of living for us, we insured to sick babies and children a new way of living with allergy, when not turning away. In figures 1-3, it is shown a quick lymphomonocytic response with a great number of lymphocites already at the second hour after the provocation test. In addition there are several monocytes showing plasmocytic aspects, immunoblasts, eosinophils and basophils.

\section{References}

1. Cantani A (2011) Lesson held at the Catholic University on Pediatric Allergy and Immunology.

2. Bahna SL, Heiner DC (1980) Allergies to milk. Grune and Stratton: New York, USA.

3. Cantani A (2000) Allergologia e Immunologia Pediatrica. Verduci Editore: Roma, Italy.

4. Cantani A (2008) Pediatric Allergy, Asthma and Immunology. Springer Heidelberg, USA.

5. Cantani A, Micera M (2011) A study on 300 asthmatic children, 300 controls and their parents confirms the genetic transmission of allergy and asthma. Eur Rev Med Pharmacol Sci 15(9): 1051-1056.

6. Nwaru BI, Erkkola M, Ahonen S, Kaila M, Haapala AM, et al. (2010) Age at the Introduction of solid foods during the first year and allergic sensitization at age 5 years. Pediatrics 125(1): 50-59.

7. Cantani A (2006) A home-made, meat-based formula for feeding atopic babies: A study in 51 children. Eur Rev Med Pharmacol Sci 10(2): 6168.

8. Cantani A (1987) The struggle for breastfeeding. Ann Allergy 59(1): 84.

\section{Your next submission with Juniper Publishers will reach you the below assets}

- Quality Editorial service

- Swift Peer Review

- Reprints availability

- E-prints Service

- Manuscript Podcast for convenient understanding

- Global attainment for your research

- Manuscript accessibility in different formats

( Pdf, E-pub, Full Text, Audio)

- Unceasing customer service

Track the below URL for one-step submission https://juniperpublishers.com/online-submission.php 